\title{
Orofaciodigital syndrome type 3
}

INSERM

\section{Source}

INSERM. (1999). Orphanet: an online rare disease and orphan drug data base.

Orofaciodigital syndrome type 3. ORPHA:2752

Oral-facial-digital syndrome, type 3 is characterized by anomalies of the mouth, eyes and digits, associated with severe intellectual deficit. 